\title{
The Psychological Benefits of Scary Play in Three Types of Horror Fans
}

\author{
Coltan Scrivner ${ }^{1,2}$ \\ Marc Malmdorf Andersen ${ }^{3,4}$ \\ Uffe Schjoedt ${ }^{3,4}$ \\ Mathias Clasen ${ }^{3,5}$
}

1. Department of Comparative Human Development, The University of Chicago

2. Institute for Mind and Biology, The University of Chicago

3. Interacting Minds Centre, Aarhus University

4. School of Culture and Society, Aarhus University

5. School of Communication and Culture, Aarhus University

Address correspondence to Coltan Scrivner, Biopsychological Science Building, 940 E. 57th Street, Chicago, IL 60637. Email: cscrivner@uchicago.edu

\begin{abstract}
Why do people seek out frightening leisure activities such as horror films and haunted attractions, and does the experience benefit them in any way? In this article, we address these questions through two separate studies. In Study 1, we asked American horror fans ( $\mathrm{n}=256)$ why they like horror and identified three overall types of horror fans which we term "Adrenaline Junkies," "White Knucklers," and "Dark Copers." In Study 2, we collected data from Danish visitors at a haunted house attraction $(n=258)$ and replicated the findings from Study 1 by finding the same three types of horror fans. Furthermore, we show that these three types of horror fans report distinct benefits from horror experiences. Adrenaline Junkies reported immediate enjoyment, White Knucklers reported personal growth, and Dark Copers reported both. These results suggest that frightening leisure activities are not only an outlet for sensationseeking, and that the allure of horror may have as much to do with learning and personal growth as it has with high-arousal fun.
\end{abstract}

Abstract word count: 169

Main document word count: 7291 


\section{Introduction}

Popular culture abounds with frightening elements. Each season sees a crop of new horror movies, streaming services offer a wealth of scary shows, and video game developers churn out ever more frightening games. In addition, haunted attractions draw hundreds of thousands of guests eager for a good scare each Halloween. According to a recent large-scale survey, most people enjoy horror to some extent and those who enjoy horror the most expect it to be just as frightening as those who do not enjoy it (Clasen et al., 2020). In other words, feeling afraid is a key aspect of a good experience with horror. Why is it that people would seek out the feeling of fear, a negatively valenced and highly arousing emotion, for recreation? This conundrum, which has been dubbed "the paradox of horror," has long puzzled scholars and scientists. A variety of accounts have been proposed to explain the allure of horror. Scholars have speculated that horror offers an opportunity for confronting one's repressed desires (Dumas, 2014), for engaging in social displays of normative behavior (Zillman \& Weaver, 1996), for engaging in benign masochism (Rozin et al., 2013), or for satisfying a curiosity about category-violating monsters and suspenseful plots (Carroll, 1990).

\subsection{Play, Learning, and the Threat Simulation Account of Horror}

Recent accounts of why humans engage with horror have argued that engaging with horror can be understood as a form of scary play that functions as threat simulation for the purpose of learning (Andersen et al., 2020; Clasen, 2017; Kerr et al., 2019; Marks \& Nesse, 1994; Miller et al., forthcoming, Scrivner et al., 2021). In this framework, horror offers individuals a way to 'play with fear' by providing opportunities to engage with moderately frightening experiences in a safe context (Andersen et al. 2020, Andersen et al., 2022; Scrivner \& Christensen, 2021). Similarly, some researchers have argued that humans possess morbid curiosity - a motivation to engage with or otherwise gather information about many of the themes that are central to horror fiction, such as body disgust, the paranormal, violence, and minds of dangerous people (Oosterwijk, 2017; Scrivner, 2021a; Scrivner, 2021b). Engaging in scary play through recreational horror may be a useful way for humans to learn about dangerous phenomena and safely experience the emotional and/or behavioral responses to frightening situations (Miller et al. forthcoming; Morin et al., 2019; Sandseter \& Kennair, 2011; Scrivner 2021b; Scrivner \& Clasen 2022). More specifically, scary play offers an opportunity to engage in and practice emotion regulation strategies for dealing with negative emotions like fear and anxiety (Scrivner \& Christensen, 2021). Some evidence for this has been observed at haunted attractions, where customers have reported using specific cognitive and behavioral regulation strategies in order to regulate their fear levels (Clasen et al., 2019). Visitors at haunted attractions have also reported that the experience felt like play (Andersen et al., 2020) and visitors who expected a haunt to be scary reported being able to challenge their fears and learn about themselves (Kerr et al., 2019). Scary elements in video games have even been leveraged specifically as learning tools for the treatment of anxiety symptoms (Schoneveld et al., 2016) and can be as effective as cognitive 
behavioral therapy in reducing anxiety symptoms (Schoneveld et al., 2018; 2020). Further supporting this idea, Scrivner et al. (2021) found that horror fans reported greater psychological resilience during the early months of the COVID-19 pandemic than non-horror fans, suggesting that exposure to frightening fiction allows audiences to learn effective coping strategies that can be beneficial in real-world scenarios.

\subsection{Individual Differences in Horror Engagement}

Although the threat simulation hypothesis may provide a functional explanation for the broad, apparently paradoxical appeal of horror, it has little to say about the individual differences in enjoyment and consumption.

The most influential account of individual differences in horror engagement suggests that frightening entertainment such as horror movies and haunted attractions appeal especially to people high in sensation-seeking, sometimes referred to as adrenaline junkies. According to Zuckerman (1994), sensation-seekers strive for complex, novel, and intense experiences. Trait sensation-seeking has been shown to predict horror movie enjoyment (Cantor and Sparks, 1984; Edwards, 1984; Tamborini \& Stiff, 1987), frequency of horror film attendance (Zuckerman \& Litle, 1986), and enjoyment of scary video games (Lynch \& Martins, 2015). However, some facets of sensation-seeking are more strongly correlated with interest in horror than others. For example, the thrill and adventure-seeking subscale tends to be the least correlated with interest in horror movies while disinhibition and experience-seeking are most strongly correlated. In other words, wanting to engage in actions with actual elements of danger (thrill and adventureseeking) is weakly correlated with interest in horror movies while enjoyment of mystical and artistic thoughts (experience-seeking) and having a hedonistic social life (disinhibition) are more strongly correlated with interest in horror movies (Edwards, 1984). Likewise, Tamborini and Stiff (1987) found that interest in seeing examples of destruction and just endings is much more important than sensation-seeking in predicting the appeal of horror movies.

Even within more intense horror such as that found in haunted attractions, a sizable portion of attendees are not traditional adrenaline junkies (Clasen et al., 2019). In fact, some haunted attraction visitors even opt to minimize their fear during the experience through the use of cognitive and behavioral regulation techniques. These fear-minimizing horror fans, or "White Knucklers," are characterized by their experience of negative psychological side effects from horror such as nightmares, stress, and lingering fear (Robinson et al., 2014). Despite this, they still attend horror movies and brave their way through haunted attractions. Why would these people choose to engage with horror media? Anecdotal evidence suggests that some people benefit epistemically from horror experiences, learning something about themselves as a consequence of experiencing fear and anxiety in safe settings (e.g., Flanagan, 2020). Empirical studies on horror and violent media also support the idea that viewers engage with the media in complex ways and derive epistemic value from it (Bartsch and Mares, 2014; Bartsch et al., 
2016). Moreover, people who find horror frightening appear to benefit by challenging their fears and learning about themselves (Kerr et al., 2019). In other words, White Knucklers may be learning about themselves or developing on a personal level through engagement with recreational horror.

\subsection{The Current Studies}

The purpose of this project was to identify the possible "types" of horror fans and the selfreported benefits they derive from engagement with horror as an instance of scary play. Across two studies we developed a horror fan typology and investigated the perceived psychological benefits of engaging with horror entertainment for each type. In Study 1, we asked American participants to reflect on why they enjoyed horror films by rating a large pool of statements about why people enjoy horror. Factor analysis showed that horror fandom can be split into three distinct dimensions: Adrenaline Junkies, White Knucklers, and Dark Copers. In Study 2, we tested this typology in a field study using a different sample type in a new country. We collected data from Danish visitors at a haunted house attraction and replicated the three-factor typology from Study 1, finding that horror fans in a different culture who are engaging in $\mathrm{n}$ intense recreational horror experience can still be categorized by the same three categories. Finally, we investigated the perceived benefits of the horror experience for each fan type.

Because high sensation-seekers (Adrenaline Junkies) enjoy the extreme sensations that emerge from the suspense and fear-filled atmosphere of horror, we predicted that scoring higher on the Adrenaline Junkie factor would be positively associated with feeling good after the haunted house experience. Since Kerr et al. (2019) found that haunted house visitors who were most scared were more likely to report learning about themselves, we predicted that visitors who scored higher in the White Knuckler factor would report learning more about themselves. Because the Dark Coper factor was an expected finding in Study 1, we had no specific predictions about how it would relate to mood. However, we did expect people who used horror to cope would report that they had developed as a person during the experience.

\section{Study 1}

\section{Method}

\subsection{Participants}

US Adults $(n=403)$ were recruited via Prolific for a study on personality and media preferences. After removing 16 participants who failed attention checks, a total sample of 389 remained ( $M_{\text {age }}$ $=33 ; 57 \%$ male). 


\subsection{Measures}

Participants reported their age, sex, and the extent to which they agreed with the statement, "I enjoy watching horror movies and TV shows." Next, participants rated how much they agreed with 46 statements that focused on why people like horror movies (Supplementary Table 1). Most of these statements came from Robinson et al. (2014), who sourced them from a mix of horror-related academic articles, magazines, newspapers, blogs, fan pages, chat rooms, and online comments sections. One additional exploratory statement was also included. The statements that participants saw were about why people like horror, and our research interest was what horror fans get out of horror. Thus, we restricted our analysis to participants who liked horror, indicated by agreement (selecting greater than 4 on the 7-point scale) with the statement, "I enjoy watching horror movies and TV shows" $(\mathrm{n}=256)$.

\section{Results}

\subsection{Exploratory factor analysis}

Exploratory factor analysis (EFA) was conducted on the sample of horror fans using the psych package in R (Revelle, 2017). Six outliers were detected and removed from further analysis using Mahalanobis distance $\left(X^{2}(46)=81.40\right)$, leaving a total sample of 250 participants for EFA. A Kaiser-Meyer-Olkin (KMO) test indicated that the data were suitable for EFA (MSA $=0.88)$, and Bartlett's test demonstrated correlation adequacy $\left(X^{2}(1035)=5063.77, p<.001\right)$. Maximum likelihood estimation was used with direct oblimin rotation to examine factor structure. Visual inspection of the scree plot and parallel analysis both suggested a three-factor structure. Items with communalities below $0.20(n=8)$ were removed before assessing item loadings. Items that loaded onto more than one factor were removed in a stepwise fashion, beginning with items that loaded on all 3 factors. Items with the highest cross-loadings were removed first until no items exhibited cross-loading above 0.40 . To further reduce item number and increase robustness of the scale, items that were redundant, had moderately high cross-loadings, or low communalities were removed from Factors 1 and 2. The result was an 18-item scale with six items per factor.

The first factor consisted of items similar to those in the "Adrenaline Junkie" factor from Robinson et al. Items in this factor touched on enjoying suspense, fear, and feeling alive during horror movies. The second factor consisted of items similar to those in the "White Knuckler" factor from Robinson et al. These items center around the negative psychological effects that stem from watching horror movies, such as nightmares, feeling stressed, and feeling afraid after watching a horror film. The third factor, however, did not align with the "detective" factor from Robinson et al. Instead, items in factor 3 centered around the extreme nature of horror films and how this related to the individual's personal life. These items appeared to reflect the use of dark parts of horror as a way to understand and cope with the real world (Supplementary Table 2). For 
example, Dark Copers reported agreed with statements suggesting that horror movies remind them of how violent the world is and that they make it seem as if their own life is okay. One Dark Coper item also resembled a demonstration of self-efficacy or social bravery ("I like to prove to my friends that I'm not afraid to go to horror movies"). Because of the apparent focus on using horror as a means to cope with the existential parts of life, we refer to this factor as the "Dark Coper" factor. Each factor demonstrated good reliability (Cronbach's $a_{A J}=.83$, Cronbach's $a_{W K}=.81$, Cronbach's $\left.a_{D C}=.76\right)$. The Dark Coper factor was positively correlated with both the Adrenaline Junkie factor $(r=.35)$ and the White Knuckler factor $(r=.19)$.

\subsection{Demographics}

Participants who enjoyed horror tended to be younger ( $M_{\text {age }}=32$ vs. 35$)$, but not skewed towards either male or female (57\% male in horror fans vs $56 \%$ male in non-horror fans). Among horror fans, age did not significantly predict scores on any of the three factors ( $p_{\text {AdrenalineJunkie }}=.388$; $p$ WhiteKnuckler $=.090 ; p$ DarkCoper $=.403)$. There were no sex differences in scores on the Dark Coper Dimension. Males scored higher in the Adrenaline Junkie dimension $\left(M_{\text {male }}=4.0, M_{\text {female }}=3.7 ; p\right.$ $=.023)$ and lower in the White Knuckler dimension $\left(M_{\text {male }}=5.1, M_{\text {female }}=5.4 ; p=.023\right)$. This demographic difference is in line with evidence that men tend to score higher in sensationseeking and lower in fear.

\section{Study 2}

\section{Method}

\subsection{Participants}

Adult visitors ( $\mathrm{n}=281 ; 157$ female) were recruited prior to entering the haunted attraction. Of the 281 participants who were recruited, 258 completed both the pre-haunt and post-haunt questionnaires and were included in the analysis. Because participant sex was used in regression analyses, four participants were removed from regression analyses for reporting something other than male or female. Thirteen participants dropped out of the haunt and were not included in analyses, leaving 241 participants who were included in analyses.

\section{$2.2 \quad$ Procedure}

Participants were recruited during the 2020 Halloween season at Dystopia Haunted House, a haunted attraction in Vejle, Denmark. Visitors payed to walk (or sometimes run) in groups of two to three through dozens of interconnected rooms in an old, abandoned factory. The rooms 
were designed with props and special effects to elicit fear, anxiety, and disgust, and they were populated with scare actors whose job it was to frighten and unnerve visitors (Figure 1). The effect, from the perspective of the visitor, is one of becoming the protagonist in an immersive horror story that unfolds in real time in a physical environment replete with cues of danger. The entire experience lasted about one hour per group. Participants completed a pre-haunt questionnaire while waiting in line to enter and a post-haunt questionnaire after exiting the haunt. Participants were identified by a number worn on their chest. When completing the post-haunt questionnaire, participants could leave their email address if they wanted to be entered into a drawing to win 500 Danish krone ( \$81 USD). All questions were presented in Danish.

Figure 1. An example of the atmosphere and an actor inside the haunted attraction. Image $\odot$ Kim Kristensen/Dystopia Entertainment. Reproduced with generous permission.

\subsection{Measures}

In the pre-haunt questionnaire participants were asked to record their participant number, age, and sex. In the post-haunt questionnaire, participants first reported their participation number and whether or not they dropped out of the haunt. If they did not drop out of the haunt, they reported how much they agreed or disagreed (1 - strongly disagree, 7 - strongly agree) with three statements about their experience inside the haunt: 1) The experiences inside the haunt have made me feel good right now, 2) The experiences inside the haunt have taught me new things about myself, and 3) The experiences inside the haunt have helped me develop at a personal level. If participants reported that they learned something about themselves or developed on a personal level, they were asked to explain their answer. Participants then completed the horror typology questionnaire from Study 1. An additional item that we expected to load onto the Dark Coper factor ("Watching horror movies helps me control feelings of anxiety or depression") was included in the typology questionnaire to explore whether coping was a central theme of this new factor. Finally, participants entered their email address if they wanted to be included in the 500 krone drawing. Only participants who completed both questionnaires and did not drop out of the haunt were included $(\mathrm{n}=241 ; 137$ female).

\section{Results}

\subsection{Exploratory Factor Analysis on Horror Typology Questionnaire}

Exploratory factor analysis (EFA) was conducted on the sample of horror fans using the psych package in R (Revelle, 2017). Six outliers were detected and removed from further analysis using Mahalanobis distance $\left(X^{2}(19)=43.82\right)$, leaving a total sample of 252 participants for EFA. Bartlett's test demonstrated correlation adequacy $\left(X^{2}(171)=187.43, p<.001\right)$ and a Kaiser- 
Meyer-Olkin (KMO) test indicated that the data were suitable for EFA (MSA =0.86). Maximum likelihood estimation was used with direct oblimin rotation to examine factor structure. Visual inspection of the scree plot and parallel analysis both suggested a three-factor structure, consistent with Study 1. No items exhibited cross-loading above 0.40. (see Table 1). One Adrenaline Junkie item ("Being scared makes me feel alive") loaded slightly on Dark Copers (.37). However, this may simply reflect the extreme nature of the haunted house, in which participants who agree with this statement are more likely to attend. Alternatively, the increased arousal from the experience may have influenced responses on this question. Each factor demonstrated good reliability (Cronbach's $a_{a d r e n a l i n e}=.89$, Cronbach's $a_{w h i t e}=.83$, Cronbach's $\left.a_{\text {dark }}=.76\right)$. The Dark Coper factor was positively correlated with the Adrenaline Junkie factor $(r$ $=.44)$ and the White Knuckler factor $(r=.13$; Supplementary Table 3).

\section{Table 1}

Horror Typology with items and factor loadings from Study 2.

\begin{tabular}{|c|c|c|c|c|}
\hline Item & Statement & $\begin{array}{l}\text { Adrenaline } \\
\text { Junkie }\end{array}$ & $\begin{array}{l}\text { White } \\
\text { Knuckler }\end{array}$ & $\begin{array}{l}\text { Dark } \\
\text { Coper }\end{array}$ \\
\hline $\mathrm{AJ} 1$ & $\begin{array}{l}\text { I go to horror movies because I love the feeling of } \\
\text { being scared. }\end{array}$ & 0.72 & 0.06 & 0.06 \\
\hline $\mathrm{AJ} 2$ & $\begin{array}{l}\text { I love the adrenaline rush I get from watching } \\
\text { horror movies. }\end{array}$ & 0.85 & 0.10 & 0.05 \\
\hline $\mathrm{AJ} 3$ & $\begin{array}{l}\text { I like the sensations that watching horror movies } \\
\text { give me. }\end{array}$ & 0.81 & -0.08 & 0.07 \\
\hline AJ4 & I like horror movies because they are suspenseful. & 0.79 & 0.02 & 0.03 \\
\hline AJ5 & Being scared makes me feel alive. & 0.42 & 0.11 & 0.37 \\
\hline AJ6 & $\begin{array}{l}\text { I like that feeling of not knowing what's going to } \\
\text { happen next in a horror movie. }\end{array}$ & 0.78 & -0.09 & -0.10 \\
\hline WN1 & I have nightmares after watching horror movies. & -0.24 & 0.65 & 0.06 \\
\hline WN2 & $\begin{array}{l}\text { I've gotten so scared during a horror movie that I } \\
\text { was afraid to go home or walk in my house } \\
\text { afterwards. }\end{array}$ & 0.17 & 0.79 & -0.07 \\
\hline WN3 & $\begin{array}{l}\text { I can feel myself becoming physically stressed } \\
\text { while watching a horror movie. }\end{array}$ & 0.02 & 0.65 & 0.09 \\
\hline
\end{tabular}


The effects of horror movies linger with me for

WN4 months or even years.

0.57

0.21

Even though I know horror movies aren't real I

WN5 still get really scared while watching them.

0.07

0.80

I hate the feeling when I'm watching a horror

movie and I know something bad is about to

WN6 happen.

$-0.23$

$\mathbf{0 . 4 5}$

0.19

I like to watch "torture films" because I am curious

DC1 what torture would really be like.

0.12

$-0.19$

0.49

The more blood and gore there is in a horror movie

DC2 the better.

0.14

$-0.25$

0.45

Watching horror movies is a way for me to cope

DC3 with the real world.

0.14

0.13

0.51

Horror movies remind me of how violent the world

DC4 is today.

0.12

0.64

Watching horror movies makes me realize that

DC5 everything in my own life is OK.

0.10

0.15

0.45

I like to prove to my friends that I'm not afraid to

DC6

go to horror movies.

0.01

$-0.08$

0.56

Watching horror movies helps me control feelings

DC7 of anxiety or depression.

0.15

$-0.06$

0.61

Cronbach's alpha

.89

.83

.76

Inter-item Correlation (M)

.57

.45

.31

Percent of explained variance

$41 \%$

$32 \%$

$27 \%$

Note. Item loadings above .40 are bolded.

\subsection{Mood boosts, learning, and developing as a person}

We had three main outcome variables for Study 2 that represent three of the possible benefits that recreational horror may provide to consumers. First, some people who engage in recreational horror may experience a mood boost. Second, some may feel like they learned something about themselves during the experience. Finally, some users may feel as if they developed as a person during the experience. The latter two outcomes are related but could tap into distinct benefits. 
One may learn something about oneself (e.g., I am afraid of horror or I am not afraid of horror). In this case, self-knowledge itself is the benefit. Developing as a person, however, suggests that the person improves some ability (e.g., I learned how to overcome my fears). While we did ask participants to explain their answer if they reported learning about themselves or developing as a person, translation issues and incomplete responses rendered a systematic analysis untenable (see https://osf.io/24x5k/?view_only=4197ccf2721f413c908ae1ece23e5aea for participant explanations).

We tested the association between each of these outcomes and scores on each factor of the horror typology. We predicted that Adrenaline Junkies would report greater mood boosts and White Knucklers would report feeling as if they learned something about themselves or developed as a person. Because the Dark Coper factor was an unexpected finding in Study 1, we had no specific predictions about how it would relate to mood. However, we did expect people who used horror to cope to report that they had developed as a person or learned something during the experience. To reduce the chance of false positives in our correlation analysis, we implemented the Bonferroni correction. Therefore, our alpha for determining significance of the correlations was $p<0.017$ (0.05 / 3 tests per variable). From a basic correlation analysis (Table 2), each of our predictions was confirmed. We found that Adrenaline Junkies were more likely to report a mood boost, White Knucklers were more likely to report learning something about themselves and feeling as if they developed as a person, and Dark Copers were more likely to report all three outcomes. To test how robust the findings were, we conducted a linear regression model for each outcome variable with the three dimensions of the horror typology as IVs and controlling for participant age and sex (Supplementary Table 4).

\section{Table 2}

Correlation matrix for horror typology and outcome variables.

\begin{tabular}{lccc}
\hline & Learn & Develop & Mood Boost \\
\hline $\begin{array}{l}\text { Adrenaline } \\
\text { Junkie }\end{array}$ & .05 & .09 & $\mathbf{. 2 6}^{* * *}$ \\
\hline $\begin{array}{l}\text { White } \\
\text { Knuckler }\end{array}$ & $\mathbf{. 2 0}^{* *}$ & $\mathbf{. 2 3}^{* * * *}$ & -.05 \\
\hline $\begin{array}{l}\text { Dark } \\
\text { Coper }\end{array}$ & $\mathbf{. 0}^{* *}$ & $\mathbf{. 3}^{* * *}$ & \\
\hline
\end{tabular}

Note. Bold indicates a significant correlation. $* *$ indicates $\mathrm{p}<.005 ; * * *$ indicates

$\mathrm{p}<.001$. 


\subsubsection{Feeling good due to your experience in the haunt}

We first tested the relationship between scores on the horror typology and participants feeling good due to the experience in the haunt while controlling for participant age and sex. Consistent with our preliminary analysis, those who scored high on the Adrenaline Junkie factor $(b=0.24$, $S E=0.09, t=2.84, p=.005)$ and Dark Coper factor $(b=0.28, S E=0.12, t=2.36, p=.019)$ reported a mood boost due to their experience inside the haunt. On the other hand, those who scored high on the White Knuckler factor did not report a mood boost due to their experience inside the haunt $(b=-0.01, S E=0.09, t=-0.17, p=.867)$. Age and sex had no significant effect.

\subsubsection{Learning about yourself from your experience in the haunt}

Next, we tested the relationship between scores on the horror typology and participants reporting that they learned something about themselves due to the experience in the haunt. Controlling for participant age and sex, we found that those who scored high on the White Knuckler factor $(b=$ $0.19, S E=0.09, t=2.23, p=.027)$ and Dark Coper factor $(b=0.31, S E=0.12, t=2.53, p=$ .012) reported that they learned something about themselves due to their experience inside the haunt. However, those who scored high on the Adrenaline Junkie factor did not report learning anything about themselves $(b=-0.04, S E=0.09, t=-0.46, p=.646)$. Age and sex had no significant effect.

\subsubsection{Developing as a person from your experience in the haunt}

Finally, we tested the relationship between scores on the horror typology and participants reporting that they developed as a person due to the experience in the haunt. Results mirrored the learning outcome. Controlling for participant age and sex, we found that those who scored high on the White Knuckler factor $(b=0.21, S E=0.08, t=2.70, p=.008)$ and Dark Coper factor $(b=$ $0.49, S E=0.11, t=4.53, p<.001)$ reported that they developed as a person due to their experience inside the haunt. On the other hand, those who scored high on the Adrenaline Junkie factor did not report that they developed as a person due to their experience inside the haunt $(b=$ $-0.05, S E=0.08, t=0.64, p=.523)$. Age and sex had no significant effect.

\section{Discussion}

Across two samples in the US (self-identified horror fans online) and Denmark (visitors at a haunted attraction), we found that horror fans fall along three dimensions or types: Adrenaline Junkies, White Knucklers, and Dark Copers. Each of these types is characterized by being drawn to horror for different reasons. Furthermore, they report different benefits from recreational horror in the context of a haunted attraction. 


\subsection{Adrenaline Junkies}

Studies 1 and 2 corroborate the widespread assumption that some horror fans can be characterized as Adrenaline Junkies because they enjoy the intense experience that can result from recreational horror. Previous studies on horror fandom have identified Adrenaline Junkies as one of the primary types of horror fans (Clasen et al., 2019; Robinson et al., 2014). Those who scored high on the Adrenaline Junkie dimension agreed with statements such as "I go to horror movies because I love the feeling of being scared" and "I like the sensations that watching horror movies gives me." Given the pleasure they derive from the strong sensations that horror offers, the Adrenaline Junkies are in many ways analogous to those who score high in sensationseeking.

These results are compatible with several studies on horror fandom reporting a positive, though small, correlation with sensation-seeking (e.g., Clasen et al., 2020; Hoffner \& Levine, 2005; Lynch \& Martins, 2015; Tamborini \& Stiff, 1987; Zuckerman \& Litle, 1986). Individuals who score high in sensation-seeking experience positive emotions in response to high arousal, including arousal stemming from negative stimulation due to fear (Zaleski, 1984; Zuckerman, 1979). Our results in Study 2 support this account as well. Visitors at the haunted house who scored higher in the Adrenaline Junkie dimension reported feeling good due to their experiences inside the haunt. Like the feel-good rush they experience after skydiving (Dustin et al., 2019), Adrenaline Junkies experience a feel-good rush in the face of dangerous or seemingly dangerous situations.

\subsection{White Knucklers}

Studies 1 and 2 also support the existence of another type of horror fan, the so-called White Knuckler. Like Adrenaline Junkies, White Knucklers report feeling afraid during recreational horror; where they differ from Adrenaline Junkies is in how they appraise the sensation. White Knucklers do not get immediate pleasure from feeling afraid, agreeing with statements such as "I hate the feeling when I'm watching a horror movie and I know something bad is about to happen" and "I have nightmares after watching horror movies." Though they have been previously identified in studies on horror fandom (Clasen et al., 2019; Robinson et al., 2014), far less research has been conducted on White Knucklers than on Adrenaline Junkies.

If White Knucklers dislike the sensations associated with feeling afraid, why would they seek out entertainment that is designed to scare? One possibility is that, instead of getting immediate, pleasurable rewards from frightening stimuli, White Knucklers achieve an epistemic benefit from a recreational horror experience. Accordingly, we predicted that some horror fans might emphasize learning-based benefits that come after a recreational horror experience rather than emphasizing the feelings that result from recreational horror. 
In support of our prediction, visitors at the haunted house who scored high in the White Knuckler dimension reported that they felt they learned something about themselves and developed as a person due to their experience inside the haunt. Unlike Adrenaline Junkies, White Knucklers may not enjoy being attacked by a monster in the moment (Figure 1). However, after the frightening encounter ends, White Knucklers are more likely to find some epistemic value in the experience. By exposing themselves to fearful, but safe, situations, White Knucklers can learn important lessons about how they might respond to other fearful or high-intensity situations.

Figure 2. Responses to a scare caught during a flash. Some visitors were more visibly frightened in response to frightening moments like the one pictured here. Image @ $\odot$ Dystopia Entertainment, reproduced with generous permission from Dystopia Entertainment and the guests depicted in the image.

\subsection{Dark Copers}

Study 1 uncovered a new and surprising third type of horror fan, which we term "Dark Copers." This type also appeared in the Danish sample in Study 2. Dark Copers are characterized by feeling that horror helps them cope with existential problems. Dark Copers agreed with statements such as "horror movies remind me of how violent the world is today" and "watching horror movies helps me control feelings of anxiety or depression." Interestingly, Dark Copers appear to both get immediate, pleasure-related benefits from horror like the Adrenaline Junkies and epistemic benefits like the White Knucklers. In other words, scoring high in the Dark Coper dimension was positively correlated with all three outcome variables in Study 2; being more of a Dark Coper was positively associated with feeling good due to the intense experience in the haunt, feeling like you learned something about yourself, and feeling like you developed as a person. It appears that this previously uncharted type of horror fan may have the most to benefit from recreational horror.

There is still much to be discovered about this third dimension of horror fandom. It is possible, for instance, that the self-reflection that occurs after recreational horror is different in Dark Copers and White Knucklers. Whereas White Knucklers may learn the limits of their fears, the prototypical Dark Coper seems to approach recreational horror in a way that displays both excitement and existential coping. Indeed, some of the learning that Dark Copers experience seems to be akin to that which motivates morbid curiosity (Scrivner 2021b). For example, Dark Copers agree with the statement, "I like to watch "torture films" because I am curious what torture would really be like." Dark Copers may also be a group that is of interest to clinical psychologists. Anecdotal evidence suggests that some individuals may find solace from their anxiety and depression through using horror entertainment (e.g., Grisafi 2016; Turner 2017), which aligns well with the core of the Dark Coper. Correspondingly, Scrivner and Christensen (2021) have argued that horror possesses cognitive attractors for individuals with elevated 
anxiety and may hold therapeutic value by offering a safe way to practice emotion regulation and develop psychological resilience (see also Sandseter \& Kennair, 2011; Scrivner et al., 2021).

\subsection{Unfolding the Paradox of Horror: Limitations and Future Directions}

Engaging with simulated threats in playful scenarios seems to confer different benefits to different people. For some, engaging with horror media confers reward-based enjoyment, whereas for others the main benefit is based in learning or self-development. One way to think about the distribution of perceived psychological benefits is on a scale of short-term to longterm. Adrenaline Junkies receive short-term benefits from recreational horror - they enjoy the extreme sensations in the moment. White Knucklers, in contrast, may benefit on a longer-term scale. By pushing their boundaries, they may benefit in the long run through learning something about themselves and experiencing a sort of personal growth. Finally, Dark Copers report benefiting the most broadly. They relish the scares in the moment like Adrenaline Junkies, but also reflect on the experience and feel as if they have gleaned personal insight and experienced personal growth like the White Knucklers.

While previous studies have documented some of the reasons why certain horror fans get enjoyment from frightening entertainment (e.g., Andersen et al., 2020; Andrade \& Cohen, 2007; Tamborini \& Weaver, 1996), the benefits from horror in terms of learning something about oneself and attaining personal growth are still underspecified. It is possible that White Knucklers and Dark Copers differ in terms of what they learn about themselves and what they gain in personal growth. Our quantitative results tell us little about what it is that White Knucklers and Dark Copers specifically feel they learn about themselves and how they feel that they benefit in terms of personal growth. However, qualitative data collected for Study 2 gives a few indications.

One participant who reported learning about themself explained: "[I was s]urprised by how scared I actually got. So maybe I've learned that I can't be completely certain about what my fears are before I'm in the situation." Another participant said that they learned that they were "good at handling stressful situations and act[ing] rationally." While this qualitative data suggests that outcomes vary between individuals, the qualitative data collected for the purpose of this study was too incomplete to render a systematic analysis. Future studies may thus benefit from attempting to systematically investigate the possible differences in the types of things some horror fans learn about themselves when engaging with horror and the ways in which they feel that they grow as a person.

Finally, another limitation might be that the items on the horror typology scale ask about horror movies. It can be argued, however, that the scale items capture something relatively central to adults' motivation to engage in scary play regardless of context. Horror movies are presumably the most common form of horror engagement and questions about them may be easier for a 
participant to ponder than more general or abstract questions about horror as a genre. If adults' motivations for engaging in scary play are being measured by the scale, then the results may not be strongly affected by a change in recreational horror type. Indeed, we found the same factorization of items when surveying American participants online and Danish participants at a haunted house. Still, it may be useful for researchers to verify these assumptions and for future studies to compare more generalized wording to context-specific wording of the scale.

\subsection{Conclusion}

Past research on individual differences in horror entertainment has focused heavily on high sensation-seeking as an explanation for horror's popularity. However, our studies reveal three distinct types of horror fans: Adrenaline Junkies, White Knucklers, and Dark Copers. These three types of horror fans enjoy horror for different reasons and report different benefits after engaging with recreational horror. Adrenaline Junkies report immediate enjoyment from engaging with recreational horror, while White Knucklers report that they mainly learn about themselves and develop as a person from the experience. We also discovered a third category, the Dark Copers, who report experiencing both immediate enjoyment from engaging in recreational horror as well as personal learning and development. These findings help identify the diversity in horror consumers and their perceived benefits from engaging with scary play through recreational horror.

\section{Acknowledgements}

We would like to thank our research assistants for their help with data collection for Study 2: Emilie Larsen Bro, Simon Bysted, Nilab Gholam, Majbritt Grønbæk, Anna Sofie Hauge Jacobsen, Sarah Klainberger, Jonas Bilgrav Mathiasen, Pernille Lærke Munk-Hansen, Mathilde Randlev Møller, Mads Jessen Pedersen, Emma Hove Petersen, Valborg Silberg, Signe Simonsen, Mihaela Taranu, Emma Elisabeth Thomsen, and Jannik Wiggers. We would also like to thank Marie Søndergaard and Katrine Dahl Sørensen, interns at the Recreational Fear Lab, for invaluable help with managing the data collection for Study 2, and Dystopia Entertainment for making their haunted attraction available to us.

\section{Funding}

Independent Research Fund Denmark (Mathias Clasen’s grant no. 0132-00204B).

\section{Disclosure Statement}

No potential conflict of interest was reported by the author(s). 


\section{Data availability statement}

The data described in this article are openly available in the Open Science Framework at https://osf.io/24x5k/?view only=4197ccf2721f413c908ae1ece23e5aea.

\section{References}

Andersen, M. M., Kiverstein, J., Miller, M. \& Roepstorff, A. (2022). Play in Predictive Minds. Psychological Review.

Andersen, M. M., Schjoedt, U., Price, H., Rosas, F. E., Scrivner, C., \& Clasen, M. (2020). Playing with fear: A field study in recreational horror. Psychological science, 31(12), 1497-1510. https://doi.org/10.1177\%2F0956797620972116

Andrade, E. B., \& Cohen, J. B. (2007). On the consumption of negative feelings. Journal of Consumer Research, 34(3), 283-300. https://doi.org/10.1086/519498

Bartsch, A., \& Mares, M. L. (2014). Making sense of violence: Perceived meaningfulness as a predictor of audience interest in violent media content. Journal of Communication, 64(5), 956-976. https://doi.org/10.1111/jcom.12112

Bartsch, A., Mares, M. L., Scherr, S., Kloß, A., Keppeler, J., \& Posthumus, L. (2016). More than shoot-em-up and torture porn: Reflective appropriation and meaning-making of violent media content. Journal of Communication, 66(5), 741-765. https://doi.org/10.1111/jcom.12248

Cantor, J., \& Sparks, G. G. (1984). Children's fear responses to mass media: Testing some Piagetian predictions. Journal of Communication. https://psycnet.apa.org/doi/10.1111/j.1460-2466.1984.tb02162.x

Carroll, N. (1990). The philosophy of horror: Or, paradoxes of the heart. Routledge.

Clasen, M. (2017). Why horror seduces. Oxford University Press.

Clasen, M., Andersen, M., \& Schjoedt, U. (2019). Adrenaline Junkies and White Knucklers: A quantitative study of fear management in haunted house visitors. Poetics, 73, 61-71. https://doi-org.proxy.uchicago.edu/10.1016/j.poetic.2019.01.002

Clasen, M., Kjeldgaard-Christiansen, J., \& Johnson, J. A. (2020). Horror, personality, and threat simulation: A survey on the psychology of scary media. Evolutionary Behavioral Sciences, 14(3), 213. https://psycnet.apa.org/doi/10.1037/ebs0000152 
Dumas, C. (2014). Horror and psychoanalysis: an introductory primer. A companion to the horror film, 21-37. https://doi-org.proxy.uchicago.edu/10.1002/9781118883648.ch2

Dustin, D., Zajchowski, C., \& Schwab, K. (2019). The biochemistry behind human behavior: Implications for leisure sciences and services. Leisure Sciences, 41(6), 542-549. https://doi.org/10.1080/01490400.2019.1597793.

Edwards, E. D. (1984). The relationship between sensation-seeking and horror movie interest and attendance.(Doctoral dissertation, The University of Tennessee).

Flanagan, M. (2020, April 3). Facing fear during times of uncertainty. Bloody Disgusting. https://bloody-disgusting.com/editorials/3611821/facing-fear-times-uncertainty-guestessay-filmmaker-mike-flanagan/.

Grisafi, P. (2016, January 20). How horror movies help me cope with anxiety. Luna Luna. http://www.lunalunamagazine.com/blog/how-horror-movies-help-me-copewith-anxiety

Hoffner, C. A., \& Levine, K. J. (2005). Enjoyment of mediated fright and violence: A metaanalysis. Media Psychology, 7(2), 207-237. https://doi.org/10.1207/S1532785XMEP0702_5

Kerr, M., Siegle, G. J., \& Orsini, J. (2019). Voluntary arousing negative experiences (VANE): Why we like to be scared. Emotion, 19(4), 682. https://doi.org/10.1037/emo0000470

Lynch, T., \& Martins, N. (2015). Nothing to fear? An analysis of college students' fear experiences with video games. Journal of Broadcasting \& Electronic Media, 59(2), 298317. https://doi.org/10.1080/08838151.2015.1029128

Miller, M., Andersen, M., Schoeller, F. \& Kiverstein, J. (forthcoming). Getting a kick out of film: Aesthetic pleasure and play in prediction error minimizing agents. In S. Besser \& F. Lysen (Eds.), Worlding the brain. Leiden, NL: Brill.

Morin, O., Acerbi, A., \& Sobchuk, O. (2019). Why people die in novels: testing the ordeal simulation hypothesis. Palgrave Communications, 5(1), 1-10. https://doi.org/10.1057/s41599-019-0267-0

Nesse, R. M. (1994). Fear and fitness: An evolutionary analysis of anxiety disorders. Ethology and sociobiology, 15(5-6), 247-261. https://doi.org/10.1016/0162-3095(94)90002-7

Oosterwijk, S. (2017). Choosing the negative: A behavioral demonstration of morbid curiosity. PloS one, 12(7), e0178399. https://doi.org/10.1371/journal.pone.0178399 
Robinson, T., Callahan, C., \& Evans, K. (2014). Why do we keep going back? AQ method analysis of our attraction to horror movies. Operant Subjectivity, 37(1/2), 41-57. http://dx.doi.org/10.15133/j.os.2014.004

Rozin, P., Guillot, L., Fincher, K., Rozin, A., \& Tsukayama, E. (2013). Glad to be sad, and other examples of benign masochism. Judgment and Decision Making, 8(4), 439.

Sandseter, E. B. H., \& Kennair, L. E. O. (2011). Children's risky play from an evolutionary perspective: The anti-phobic effects of thrilling experiences. Evolutionary psychology, 9(2), 147470491100900212. https://doi.org/10.1177\%2F147470491100900212

Schoneveld, E. A., Lichtwarck-Aschoff, A., \& Granic, I. (2018). Preventing childhood anxiety disorders: Is an applied game as effective as a cognitive behavioral therapy-based program?. Prevention Science, 19(2), 220-232. https://doi.org/10.1007/s11121-017-0843$\underline{8}$

Schoneveld, E. A., Malmberg, M., Lichtwarck-Aschoff, A., Verheijen, G. P., Engels, R. C., \& Granic, I. (2016). A neurofeedback video game (MindLight) to prevent anxiety in children: A randomized controlled trial. Computers in Human Behavior, 63, 321-333. https://doi.org/10.1016/j.chb.2016.05.005

Schoneveld, E. A., Wols, A., Lichtwarck-Aschoff, A., Otten, R., \& Granic, I. (2020). Mental health outcomes of an applied game for children with elevated anxiety symptoms: A randomized controlled non-inferiority trial. Journal of Child and Family Studies, 29(8), 2169-2185. https://doi.org/10.1007/s10826-020-01728-y

Scrivner, C. (2021a). An infectious curiosity: Morbid curiosity and media preferences during a Pandemic. Evolutionary Studies in Imaginative Culture, 5(1), 1-12. https://doi.org/10.26613/esic.5.1.206

Scrivner, C. (2021b). The psychology of morbid curiosity: Development and initial validation of the morbid curiosity scale. Personality and Individual Differences, 183, 111139. https://doi.org/10.1016/j.paid.2021.111139

Scrivner, C., \& Christensen, K. A. (2021). Scaring away anxiety: Therapeutic avenues for horror fiction to enhance treatment for anxiety symptoms. PsyArXiv. https://doi.org/10.31234/osf.io/7uh6f

Scrivner, C. \& Clasen, M. (2022). Why frightening imaginary worlds? Morbid curiosity and the learning potential of horror. Behavioral and Brain Sciences, 46-48. https://doi.org/10.1017/S0140525X21000923 
Scrivner, C., Johnson, J. A., Kjeldgaard-Christiansen, J., \& Clasen, M. (2021). Pandemic practice: Horror fans and morbidly curious individuals are more psychologically resilient during the COVID-19 pandemic. Personality and individual differences, 168, 110397. https://doi-org.proxy.uchicago.edu/10.1016/j.paid.2020.110397

Tamborini, R., \& Stiff, J. (1987). Predictors of horror film attendance and appeal: An analysis of the audience for frightening films. Communication Research, 14(4), 415-436. https://doiorg.proxy.uchicago.edu/10.1177\%2F009365087014004003

Tamborini, R., \& Weaver, J. B. (1996). Frightening entertainment: A historical perspective of fictional horror. Horror films: Current research on audience preferences and reactions, $1-13$.

Turner, L. (2017, August 7). 'Psycho' for the anxious: Why horror movies bring me comfort. Catapult.https://catapult.co/stories/a-cure-for-fear-psycho-for-the-anxious-whyhorrormovies-bring-me-comfort

Zaleski, Z. (1984). Sensation-seeking and risk-taking behaviour. Personality and individual Differences. https://psycnet.apa.org/doi/10.1016/0191-8869(84)90039-4

Zillmann, D., \& Weaver III, J. B. (1996). Gender-socialization theory of reactions to horror. In J. B. Weaver III \& R. Tamborini (Eds.), Horror films: Current research on audience preferences and reactions (pp. 81-101). New York: Routledge.

Zuckerman, M. (1979). Sensation seeking and risk taking. In Emotions in personality and psychopathology (pp. 161-197). Springer.

Zuckerman, M. (1994). Behavioral expressions and biosocial bases of sensation seeking. Cambridge university press.

Zuckerman, M., \& Litle, P. (1986). Personality and curiosity about morbid and sexual events. Personality and Individual Differences, 7(1), 49-56. https://doi.org/10.1016/01918869(86)90107-8

\section{Appendix}

\section{Horror Typology}

The following statements are about how you feel about horror movies. Please rate how much you agree or disagree with the following statements from 1 (Strongly Disagree) to 7 (Strongly Agree).

Item Statement 


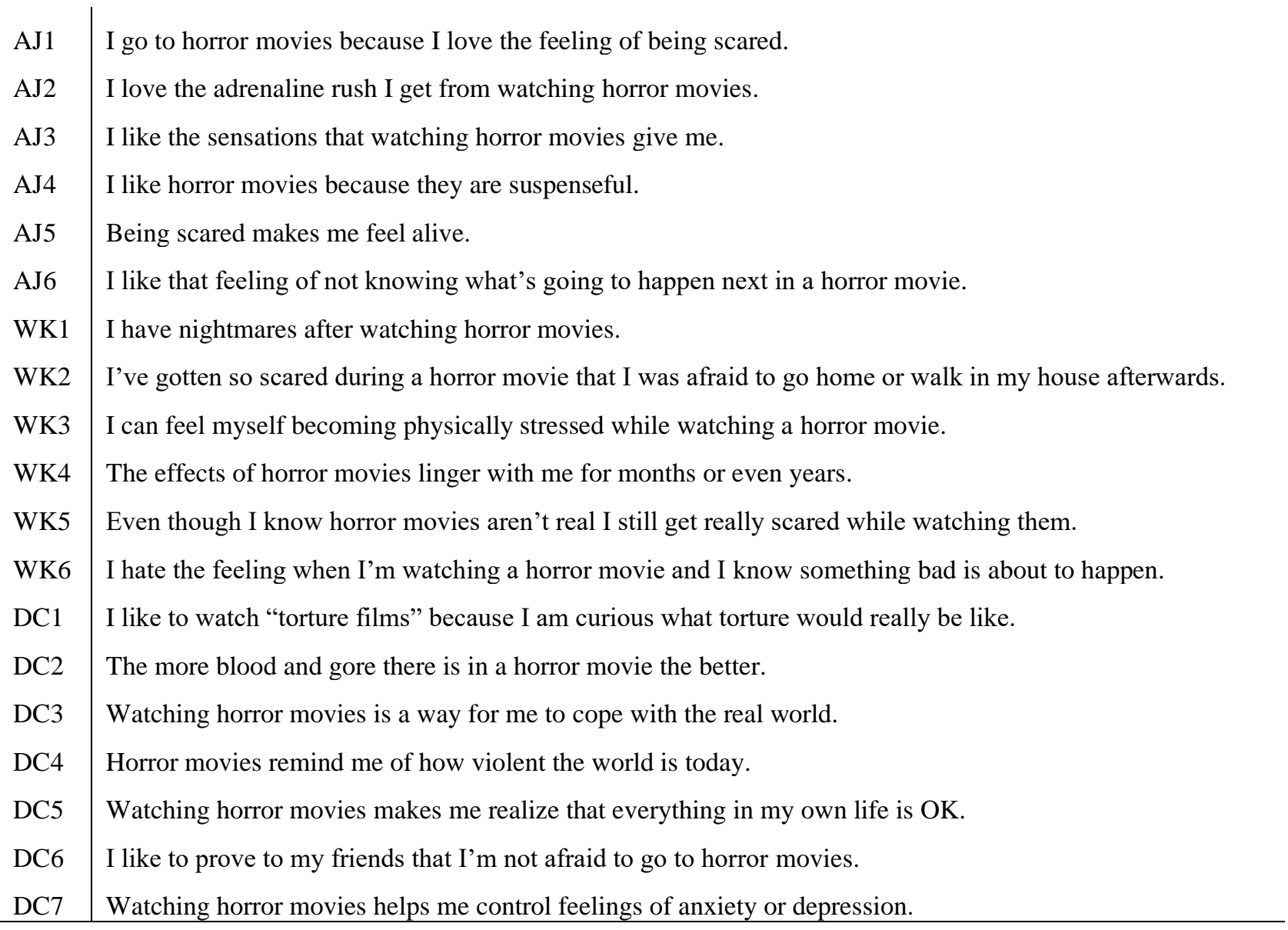




\section{Tables}

\section{Table 1}

Horror Typology with items and factor loadings from Study 2.

\begin{tabular}{|c|c|c|c|c|}
\hline Item & Statement & $\begin{array}{l}\text { Adrenaline } \\
\text { Junkie }\end{array}$ & $\begin{array}{c}\text { White } \\
\text { Knuckler }\end{array}$ & $\begin{array}{l}\text { Dark } \\
\text { Coper }\end{array}$ \\
\hline $\mathrm{AJ} 1$ & $\begin{array}{l}\text { I go to horror movies because I love the feeling of } \\
\text { being scared. }\end{array}$ & 0.72 & 0.06 & 0.06 \\
\hline $\mathrm{AJ} 2$ & $\begin{array}{l}\text { I love the adrenaline rush I get from watching } \\
\text { horror movies. }\end{array}$ & 0.85 & 0.10 & 0.05 \\
\hline $\mathrm{AJ} 3$ & $\begin{array}{l}\text { I like the sensations that watching horror movies } \\
\text { give me. }\end{array}$ & 0.81 & -0.08 & 0.07 \\
\hline AJ4 & I like horror movies because they are suspenseful. & 0.79 & 0.02 & 0.03 \\
\hline AJ5 & Being scared makes me feel alive. & 0.42 & 0.11 & 0.37 \\
\hline AJ6 & $\begin{array}{l}\text { I like that feeling of not knowing what's going to } \\
\text { happen next in a horror movie. }\end{array}$ & 0.78 & -0.09 & -0.10 \\
\hline WN1 & I have nightmares after watching horror movies. & -0.24 & 0.65 & 0.06 \\
\hline WN2 & $\begin{array}{l}\text { I've gotten so scared during a horror movie that I } \\
\text { was afraid to go home or walk in my house } \\
\text { afterwards. }\end{array}$ & 0.17 & 0.79 & -0.07 \\
\hline WN3 & $\begin{array}{l}\text { I can feel myself becoming physically stressed } \\
\text { while watching a horror movie. }\end{array}$ & 0.02 & 0.65 & 0.09 \\
\hline WN4 & $\begin{array}{l}\text { The effects of horror movies linger with me for } \\
\text { months or even years. }\end{array}$ & -0.19 & 0.57 & 0.21 \\
\hline WN5 & $\begin{array}{l}\text { Even though I know horror movies aren't real I } \\
\text { still get really scared while watching them. }\end{array}$ & 0.07 & 0.80 & -0.09 \\
\hline WN6 & $\begin{array}{l}\text { I hate the feeling when I'm watching a horror } \\
\text { movie and I know something bad is about to } \\
\text { happen. }\end{array}$ & -0.23 & 0.45 & 0.19 \\
\hline DC1 & $\begin{array}{l}\text { I like to watch "torture films" because I am curious } \\
\text { what torture would really be like. }\end{array}$ & 0.12 & -0.19 & 0.49 \\
\hline
\end{tabular}


The more blood and gore there is in a horror movie

\begin{tabular}{|c|c|c|c|c|}
\hline $\mathrm{DC} 2$ & the better. & 0.14 & -0.25 & 0.45 \\
\hline DC3 & $\begin{array}{l}\text { Watching horror movies is a way for me to cope } \\
\text { with the real world. }\end{array}$ & 0.14 & 0.13 & $\mathbf{0 . 5 1}$ \\
\hline DC4 & $\begin{array}{l}\text { Horror movies remind me of how violent the world } \\
\text { is today. }\end{array}$ & -0.10 & 0.12 & 0.64 \\
\hline DC5 & $\begin{array}{l}\text { Watching horror movies makes me realize that } \\
\text { everything in my own life is OK. }\end{array}$ & 0.10 & 0.15 & 0.45 \\
\hline DC6 & $\begin{array}{l}\text { I like to prove to my friends that I'm not afraid to } \\
\text { go to horror movies. }\end{array}$ & 0.01 & -0.08 & 0.56 \\
\hline DC7 & $\begin{array}{l}\text { Watching horror movies helps me control feelings } \\
\text { of anxiety or depression. }\end{array}$ & 0.15 & -0.06 & 0.61 \\
\hline \multicolumn{2}{|c|}{ Cronbach's alpha } & .89 & .83 & .76 \\
\hline \multicolumn{2}{|c|}{ Inter-item Correlation (M) } & .57 & .45 & .31 \\
\hline \multicolumn{2}{|c|}{ Percent of explained variance } & $41 \%$ & $32 \%$ & $27 \%$ \\
\hline
\end{tabular}

Note. Bold indicates a significant correlation. $* *$ indicates $\mathrm{p}<.005 ; * * *$ indicates $\mathrm{p}<.001$.

Table 2

Correlation matrix for horror typology and outcome variables.

\begin{tabular}{lccc}
\hline & Learn & Develop & Mood Boost \\
\hline $\begin{array}{l}\text { Adrenaline } \\
\text { Junkie }\end{array}$ & .05 & .09 & $\mathbf{. 6}^{* * *}$ \\
\hline $\begin{array}{l}\text { White } \\
\text { Knuckler }\end{array}$ & $\mathbf{. 0}^{* *}$ & $\mathbf{. 2 3}^{* * *}$ & \\
\hline $\begin{array}{l}\text { Dark } \\
\text { Coper }\end{array}$ & $\mathbf{. 0}^{* *}$ & $\mathbf{. 3 3}^{* * *}$ & -.05 \\
\hline
\end{tabular}




\section{FIGURES}

Figure 1.

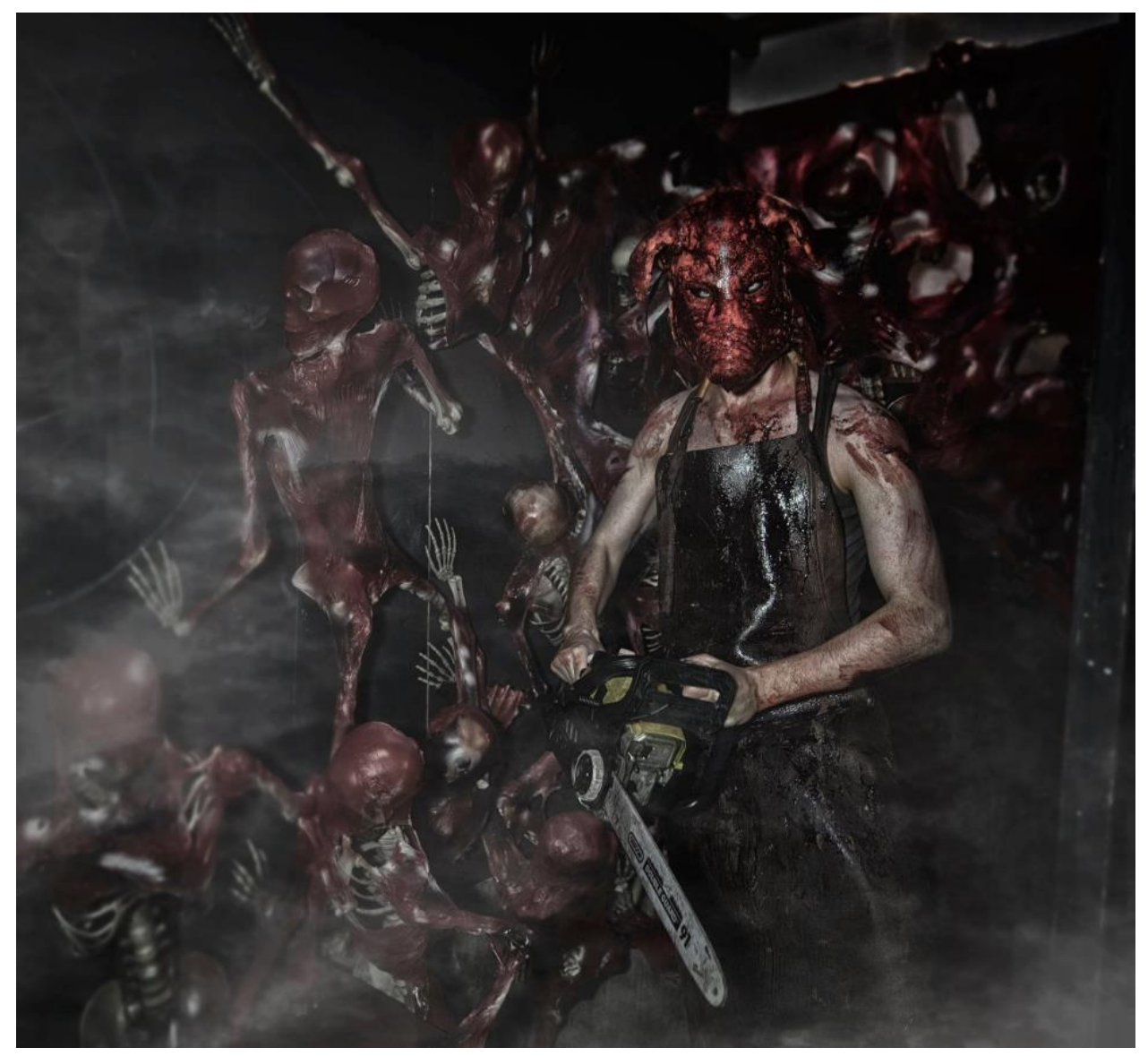


Figure 2.

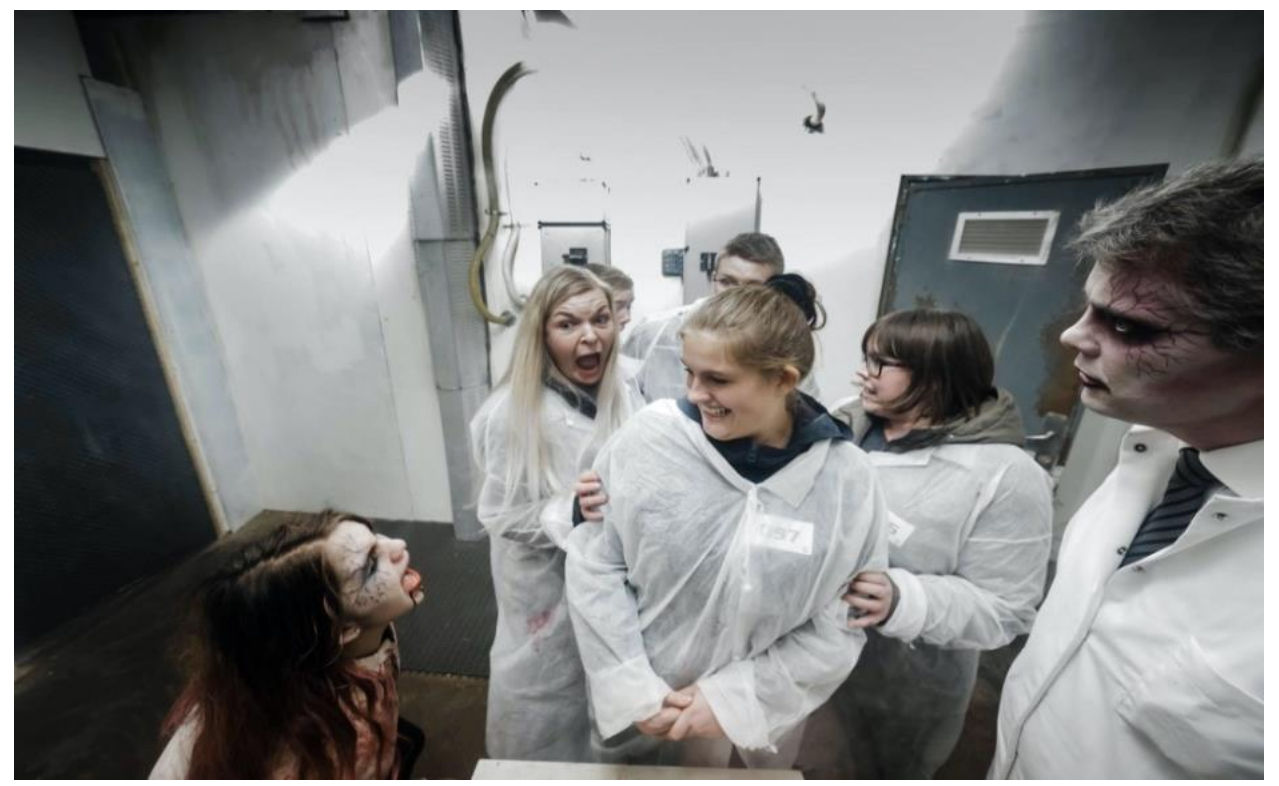

\section{CAPTIONS}

Figure 1. An example of the atmosphere and an actor inside the haunted attraction. Image $\odot$ Kim Kristensen/Dystopia Entertainment. Reproduced with generous permission.

Figure 2. Responses to a scare caught during a flash. Some visitors were more visibly frightened in response to frightening moments like the one pictured here. Image () Dystopia Entertainment, reproduced with generous permission from Dystopia Entertainment and the guests depicted in the image. 